\title{
Weight Loss, Dietary Preferences, and Reduction in the Sense of Smell with the Use of a Novel Nasal Device
}

\author{
Dror Dicker ${ }^{a}$ b Adva Beck $^{c} \quad$ Arie Markel $^{d}$ Dana Marcovicu $^{a}$ \\ Salim Mazzawi $^{\mathrm{e}}$ Miri Sarid $^{\mathrm{f}} \quad$ Elhanan Greenberg $^{\mathrm{c}}$ Richard L. Atkinson ${ }^{\mathrm{g}}$ \\ a Internal Medicine D and Obesity Clinic, Hasharon Hospital, Rabin Medical Center, \\ Petach-Tikva, Israel; b Sackler School of Medicine, Tel Aviv University, Tel Aviv, Israel; \\ 'Beck Medical, Givat-Ada, Israel; ${ }^{\mathrm{d}}$ Haemek Medical Center, Afula, Israel; ${ }^{e}$ Otolaryngology \\ Head and Neck Surgery, Haemek Medical Center, Rappaport School of Medicine, \\ Technion, Israel; fWestern Galilee College, Akko, Israel; gVirginia Commonwealth University \\ School of Medicine, Richmond, VA, USA
}

\section{Keywords}

Obesity $\cdot$ Olfactory sensitivity $\cdot$ Nasal device $\cdot$ Sense of smell $\cdot$ Dietary preferences

\begin{abstract}
Introduction: Exposure to food odors are known to increase food intake. Olfaction declines from age 50 years. Objective: We examined changes in the sense of smell, body weight, food preferences, and parameters of metabolic status, following the use of a specially designed nasal device. Methods: This is a randomized, placebo-controlled study. Participants wore a nasal device (soft silicone insert) for 5-12 h daily (device group) or inserted 2 drops of normal saline into each nostril daily (control group). Follow-up visits occurred every 2 weeks. All participants were given a $500 \mathrm{kcal} /$ day reduced diet and instructed not to change their regular physical activity. Weight, food preferences, olfactory sensitivity, and blood tests were performed at baseline and after 12 weeks. Results: Of 156 participants, 65 (42\%) completed the study. Sense of smell decreased in the device group (from $6.4 \pm 0.9$ to $4.4 \pm 1.5$, on a scale of $0-7, p<0.001)$, and did not change in the control group. Weight loss decreased by $6.6 \pm 3.7 \%$ $(p=0.001)$ and by $5.7 \pm 3.5 \%(p=0.001)$ in the respective groups (between-group difference, $p>0.05$ ). Among participants aged $\leq 50$ years, weight loss was greater in the device than in the control group $(7.7 \pm 4.2 \%$ vs. $4.1 \pm 2.9 \%, p=0.02)$. Insulin level and the homeostatic model assessment of insulin resistance (HOMA-IR) were significantly reduced in the device group ( $p=0.02$ and $p=0.01$, respectively), but not in the control group. Food preferences for sugar
\end{abstract}


$(p<0.02)$, sweet beverages $(p<0.001)$, and artificial sweeteners $(p<0.02)$ were significantly reduced in the device group compared to the control group. Conclusions: The use of a novel self-administrated nasal device led to reduced olfactory sensitivity, improved insulin sensitivity, weight loss, and lesser preference for sweets in adults aged $\leq 50$ years.

(C) 2020 The Author(s)

Published by S. Karger AG, Basel

\section{Introduction}

Obesity is a chronic relapsing disease that is associated with several complications, including diabetes, cardiovascular disease, musculoskeletal diseases, and cancer, as well as increased mortality [1-4]. The underlying mechanisms of obesity are both biological and environmental.

Olfaction is a biological factor associated with obesity. Olfaction has been shown to be intimately linked to the endocrine system and to play an integral role in regulating appetite, food intake, and body energy homeostasis [5, 6]. Additionally, the sense of smell is affected by age, hormone levels, and environmental factors. For example, olfactory sensitivity increases through young adulthood and decreases at about age 50 years [7-12]. Hormones such as ghrelin, leptin, insulin, and endocannabinoids affect olfactory perception and sensitivity, and have been shown to be affected by the olfactory system in animal models and humans $[6,13$, 14]. Insulin in the olfactory bulb affects smelling capacity, adiposity, and insulin resistance [5, $6,15,16]$. The interaction between the environment and olfaction is well-documented, especially in the presence of high fat and high sugar foods. The effect of the sense of smell on appetite and food intake has been shown to be particularly strong in people with overweight/ obesity and in restrained eaters [17-20]. Moreover, there is some evidence of this relation in adults following bariatric surgery or trauma, or in the presence of cancer. Accordingly, weight loss and change in dietary preferences were observed in the context of a reduced sense of smell [21-24].

Despite the well-known associations between olfaction, food intake, and obesity, studies examining the effect of deliberate reduction in olfaction on weight loss among people with obesity are lacking. Effects of reduced smelling capacity on food intake, obesity, and metabolic function have been documented primarily in animal research $[6,25]$.

The aim of this pilot study was to examine olfaction, body weight, food preferences, and metabolic status in people with obesity who used a novel nasal device to reduce olfaction sensation.

\section{Methods}

\section{Study Participants and Study Procedure}

A 12-week randomized, placebo-controlled study was conducted among people with obesity (BMI $30-42 \mathrm{~kg} / \mathrm{m}^{2}$ ) in 2 medical centers in Israel (Rabin Medical Center, Petach Tikva and Haemek Medical Center, Afula; NCT01534325) and approved by the Ethics Committees of both institutions.

Persons interested in participating in the study received explanations of the study design and aims and signed informed consent forms. The study inclusion criteria were age 18-65 years and BMI $30-42 \mathrm{~kg} / \mathrm{m}^{2}$. Exclusion criteria were a known anatomical or functional problem of the nose, participation in a weight reduction program during the preceding 3 months, a diagnosis of diabetes mellitus, and pregnancy. Persons who were found eligible to participate were randomized according to a 2:1 ratio to the device or control group. The 
randomization was conducted prior to the screening to enable the investigators to explain the relevant intervention (device or drops) to the potential participants. All participants underwent a physical examination and an examination by an ear, nose, and throat specialist; and they also underwent blood tests and a smelling capacity test. In addition, they met with a clinical dietician to receive counseling aimed to reduce $500 \mathrm{kcal}$ from their daily diet. Participants were instructed in using the nasal device or the nasal drops according to their group assignment. A run-in period of 7-10 days was aimed to assess compatibility with the investigational device/placebo (soft nasal insert/drops) and the capability of losing weight ( $\geq 0.5 \mathrm{~kg}$ of weight reduction was expected). All those who met the run-in criteria and who agreed to participate in the study were enrolled.

\section{Study Intervention}

The investigational device (NozNoz ${ }^{\mathrm{TM}}$, developed by Beck Medical, Israel) is composed of a soft material and inserted bilaterally into the nostrils. The device directs air into the posterior nasopharynx, bypassing the nasal olfactory epithelium. This is presumed to decrease the sense of smell. The device group was instructed to wear the nasal device for 5-12 h daily during the waking hours, for a period of 12 weeks, and to remove it before sleeping.

The control group was provided saline nose drops used as the placebo arm and were instructed to place 2 drops into their nose once a day.

All participants received dietary consultation by a trained clinical dietician. This included a baseline visit and follow-up visits every 2 weeks. At the baseline visit, the participants' diet history was reviewed and a $500 \mathrm{kcal}$ per day reduction from their usual food intake was prescribed. The dietitian provided each participant with a food diary to record food intake, and the use of the device or saline drops. Follow-up visits included a meeting with the dietitian, who evaluated the food diary, and the records of use of the device or saline drops. The participants were encouraged to adhere to the instructions they were provided. Body weight, blood pressure, and pulse were measured.

\section{Assessment of the Sense of Smell}

Olfactory ability was assessed using a smell test. Pure n-butanol was diluted with water into 7 dilutions from 4 to $0.0625 \%$, to yield a scale of 0-7. A simplified forced-choice paradigm consisting of 3 alternating options was utilized to assess smell level. A study examiner presented 3 bottles in random order, 2 bottles containing only water and the third bottle containing a dilution of n-butanol. The participants' eyes were blindfolded. Each bottle was held at $2 \mathrm{~cm}$ from the participant's nose for $3 \mathrm{~s}$. The lowest concentration of n-butanol was presented first and at each concentration at which the participant could not identify the n-butanol, the next higher concentration was presented until s/he correctly identified the bottle that held the chemical. The test was then repeated 3 times at the same dilution level to confirm the olfactory threshold. If the bottle with the chemical was not identified correctly, the next higher concentration was presented, and so forth, until the same concentration level was recognized for 4 consecutive trials. Twenty minutes after completion of the baseline smell test, the nasal device was inserted or the 2 drops of saline applied to each nostril. The smell tests were then repeated. Smell was scored on a scale of $0-7$, where a high score indicated better smell [26].

Blood was drawn for laboratory tests at baseline and at the end of the study. Fasting lowdensity lipoprotein, high-density lipoprotein, total cholesterol, triglycerides, glucose, and insulin were measured. All laboratory tests were performed by local laboratories. Insulin resistance was calculated by the homeostatic model assessment of insulin resistance (HOMA-IR) [24].

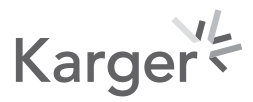


Figure 1- Participant flow chart

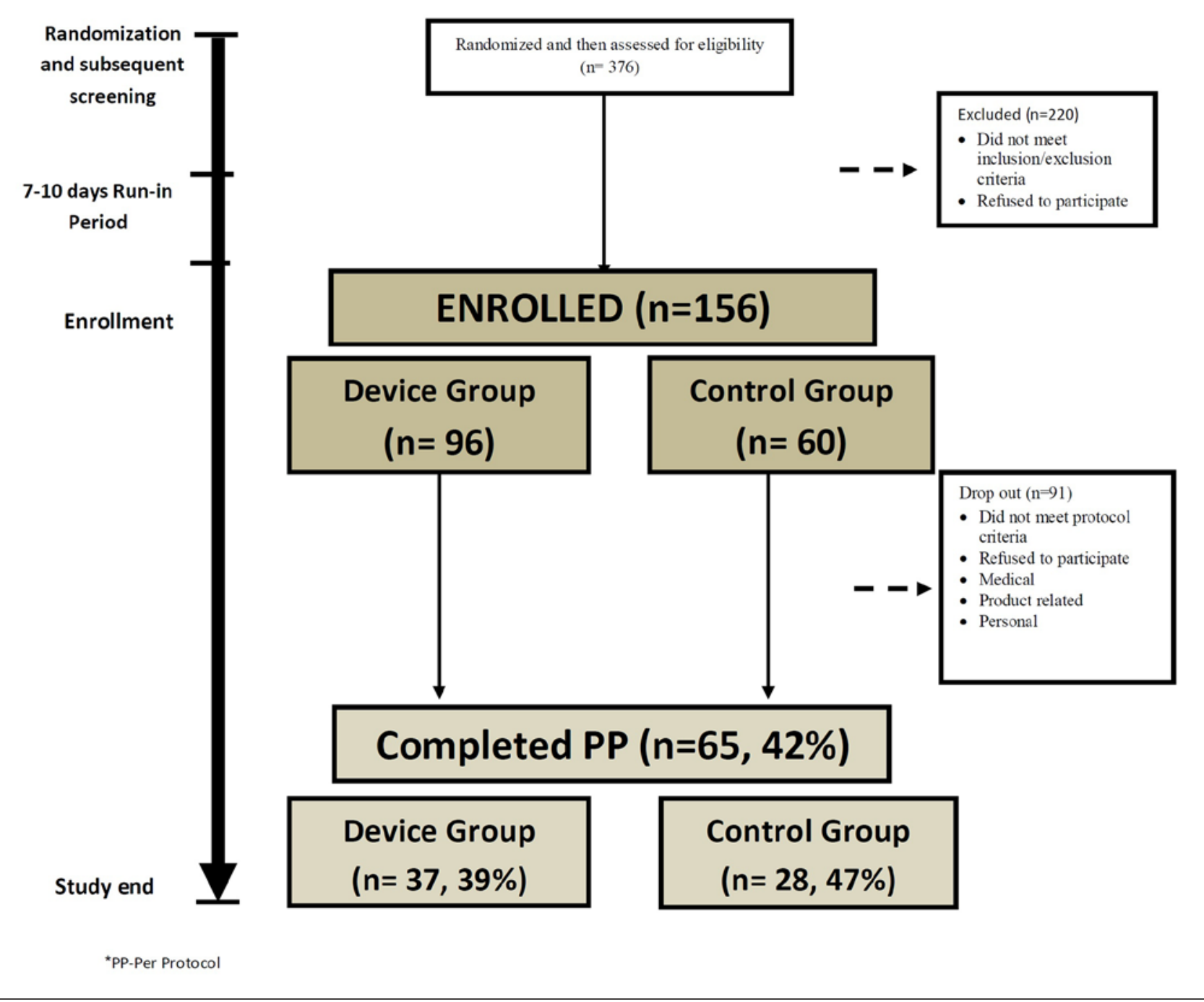

Fig. 1. Participant flow chart. This figure describes the flow of participants in the intervention and control group from screening through enrollment and completion of the study.

The participants completed a questionnaire that was designed to assess dietary habits. Assessment was according to the dietary alteration score, as described by Aschenbrenner et al. [24].

\section{Statistical Analysis}

Descriptive statistics were performed on the overall sample, and according to the intervention groups. Baseline characteristics were compared between the intervention groups using the $\chi^{2}$ test for categorical variables and $t$ tests for continuous variables. Age was assessed as a covariate (continuously) as well as by stratifying the cohort by $\leq 50$ versus $>50$ years. The effect of age was assessed by examining the interaction of the age groups with the intervention groups. The percentage of weight reduction was the primary outcome of the study. 
Table 1. Baseline characteristics of the study participants, according to the intervention and age groups

\begin{tabular}{|c|c|c|c|}
\hline & Device group & Control group & $p$ value \\
\hline \multicolumn{4}{|c|}{ Number } \\
\hline$\leq 50$ & 16 & 13 & \\
\hline$>50$ & 21 & 15 & \\
\hline All & 37 & 28 & \\
\hline \multicolumn{4}{|c|}{ Age, years } \\
\hline$\leq 50$ & $42.2 \pm 5.75$ & $40.4 \pm 7.47$ & NS \\
\hline$>50$ & $59.5 \pm 4.18$ & $57.6 \pm 4.14$ & NS \\
\hline All & $52.0 \pm 9.97$ & $49.6 \pm 10.49$ & NS \\
\hline \multicolumn{4}{|c|}{ Weight, kg } \\
\hline$\leq 50$ & $106.0 \pm 11.30$ & $101.6 \pm 13.44$ & NS \\
\hline$>50$ & $99.6 \pm 14.96$ & $104.3 \pm 13.41$ & NS \\
\hline All & $102.4 \pm 13.7$ & $103.0 \pm 13.2$ & NS \\
\hline \multicolumn{4}{|c|}{ BMI, $\mathrm{kg} / \mathrm{m}^{2}$} \\
\hline$\leq 50$ & $35.9 \pm 2.7$ & $36.5 \pm 4.4$ & NS \\
\hline$>50$ & $36.1 \pm 3.8$ & $36.1 \pm 3.2$ & NS \\
\hline All & $36.0 \pm 3.4$ & $36.3 \pm 3.7$ & NS \\
\hline \multicolumn{4}{|c|}{ Insulin, $\mu \mathrm{U} / \mathrm{mL}$} \\
\hline$\leq 50$ & $14.4 \pm 9.8$ & $10.7 \pm 4.4$ & NS \\
\hline$>50$ & $10.9 \pm 5.5$ & $11.3 \pm 4.5$ & NS \\
\hline All & $12.3 \pm 7.6$ & $11.0 \pm 4.4$ & NS \\
\hline \multicolumn{4}{|c|}{ HOMA-IR } \\
\hline$\leq 50$ & $3.6 \pm 2.4$ & $2.6 \pm 1.2$ & NS \\
\hline$>50$ & $2.4 \pm 1.3$ & $2.9 \pm 1.3$ & NS \\
\hline All & $2.9 \pm 1.9$ & $2.7 \pm 1.2$ & NS \\
\hline \multicolumn{4}{|c|}{ Glucose, mg/dL } \\
\hline$\leq 50$ & $92.2 \pm 7.1$ & $94.2 \pm 8.6$ & NS \\
\hline$>50$ & $96.0 \pm 11.9$ & $101.0 \pm 11.8$ & NS \\
\hline All & $94.4 \pm 10.2$ & $94.2 \pm 10.8$ & NS \\
\hline \multicolumn{4}{|c|}{ Cholesterol, mg/dL } \\
\hline$\leq 50$ & $180.1 \pm 70.8$ & $191.8 \pm 37.6$ & NS \\
\hline$>50$ & $200.6 \pm 29.0$ & $203.2 \pm 41.4$ & NS \\
\hline All & $190.7 \pm 48.3$ & $192.2 \pm 37.5$ & NS \\
\hline \multicolumn{4}{|c|}{$\mathrm{LDL}, \mathrm{mg} / \mathrm{dL}$} \\
\hline$\leq 50$ & $110.1 \pm 45.7$ & $119.4 \pm 26.4$ & NS \\
\hline$>50$ & $124.1 \pm 26.6$ & $125.4 \pm 40.4$ & NS \\
\hline All & $118.5 \pm 35.4$ & $115.8 \pm 30.6$ & NS \\
\hline \multicolumn{4}{|c|}{$\mathrm{HDL}, \mathrm{mg} / \mathrm{dL}$} \\
\hline$\leq 50$ & $43.2 \pm 15.5$ & $50.6 \pm 20.4$ & NS \\
\hline$>50$ & $54.3 \pm 19.9$ & $53.6 \pm 24.7$ & NS \\
\hline All & $49.8 \pm 18.8$ & $50.5 \pm 20.9$ & NS \\
\hline \multicolumn{4}{|c|}{ Triglycerides, mg/dL } \\
\hline$\leq 50$ & $127.4 \pm 61.3$ & $108.3 \pm 32.4$ & NS \\
\hline$>50$ & $114.5 \pm 50.0$ & $142.2 \pm 76.5$ & NS \\
\hline All & $119.7 \pm 54.1$ & $132.6 \pm 69.5$ & NS \\
\hline
\end{tabular}

BMI, body mass index; HDL, high-density cholesterol; HOMA-IR, homeostasis model assessment: insulin resistance; LDL, low-density cholesterol; M, mean; SD, standard deviation.

Outcomes of the device versus control groups were analyzed using three-way repeatedmeasures ANOVA. The independent factors in the analysis were grouped by time by age. Repeated-measures analyses were performed to examine within and between group ( $\leq 50 \mathrm{vs.}$ $>50$ years) differences at baseline and at the end of the 12 -week intervention; and to examine differences between the interventions (device vs. control). The interaction of group by intervention was assessed. The interaction of group by intervention by age ( $\leq 50$ vs. $>50$ years) 
was also assessed. T tests were conducted to identify variables that differed significantly $(p<0.05)$. Confirmatory analyses were conducted that incorporated baseline values as covariates for examining differences in group effects. The alpha level that was used as a criterion for statistical significance was 0.05 .

Additional analyses for characterizing the pattern of weight reduction during the study were conducted, using trend analysis to test the linear to 8th order effect among both intervention groups, with age ( $\leq 50$ and $>50$ years old) as an additional intervening factor. The analyses were conducted for weight loss, body weight, and BMI and included the baseline values. All analyses used SPSS software, version 24 (IBM SPSS Statistics for Windows, version 24.0. Armonk, NY: IBM Corp. released 2015).

\section{Results}

\section{Study Participants}

A total of 376 persons were screened for participation in the study. During the screening and run-in period, 220 persons were found not to meet the inclusion criteria or were not willing to participate, 165 persons from the device and 55 persons from the control groups. The final study cohort at baseline was 156 persons (device group, $n=96$; control group, $n=$ 60 ). A total of 65 persons (device group, $n=37$; control group, $n=28$ ) completed the study per protocol (total, 42\%; device group, 39\%; control group, 47\%; Fig. 1). Baseline characteristics of the overall sample and the intervention groups, and stratification by age group are presented in Table 1.

\section{Comfort and Safety of the Device}

Eighty-five percent of the participants aged $\leq 50$ years and $65 \%$ of participants age $>50$ years rated the device as comfortable or very comfortable. No serious adverse events were reported during the study.

\section{Change in Sense of Smell}

After insertion of the nasal device, the mean score on the n-butanol smell test decreased significantly: from $6.4 \pm 0.9$ to $4.4 \pm 1.5(p<0.001)$. No significant difference was observed in the smell test in the control group, after receiving 2 drops of saline. For both intervention groups, mean scores on the n-butanol smell test did not differ between the older and younger participants.

\section{Weight Loss}

Significant weight loss from baseline to the end of the study was observed in both the device and control groups, $-6.6 \pm 3.7 \%$ and $-5.7 \pm 3.5 \%$, respectively. The difference between the groups was not statistically significant (Table 2). The interaction effects of the intervention and age on weight loss, percentage of body weight loss, BMI, and excess weight loss were all statistically significant ( $p=0.005,0.01,0.007,0.01$, respectively). For participants aged $\leq 50$ years, the percentage of weight loss was greater for the device than the control group ( $7.7 \pm 4.2 \%$ vs. $4.1 \pm 2.9 \%, p<0.02$; Fig. 2$)$. For this age group, the mean reductions in excess body weight were $26 \pm 13.6 \%$ and $13 \pm 8.8 \%$ for the respective intervention groups ( $p=0.01)$; and BMI decreased by $2.9 \pm 1.8 \mathrm{~kg} / \mathrm{m}^{2}$ and $1.6 \pm 1.3 \mathrm{~kg} / \mathrm{m}^{2}(p<$ 0.03 ), respectively (Table 2; Fig. 2). For participants aged $\geq 50$ years, weight loss did not differ between the intervention groups. Among participants aged $\leq 50$ years who used the device for an average of $>8 \mathrm{~h}$ daily $(n=9)$, the mean weight loss was $10.1 \mathrm{~kg}$ during the trial period.

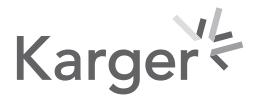




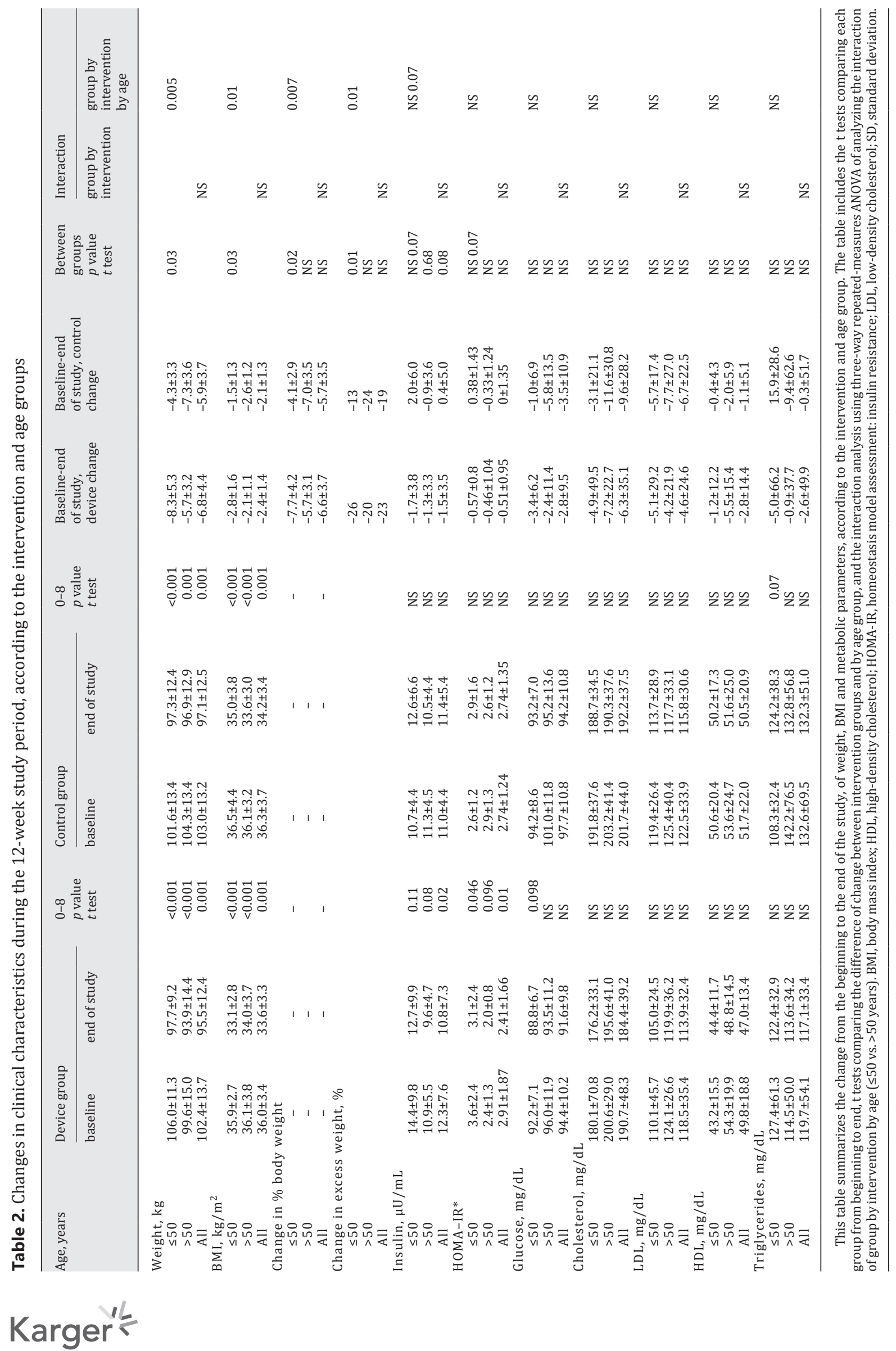



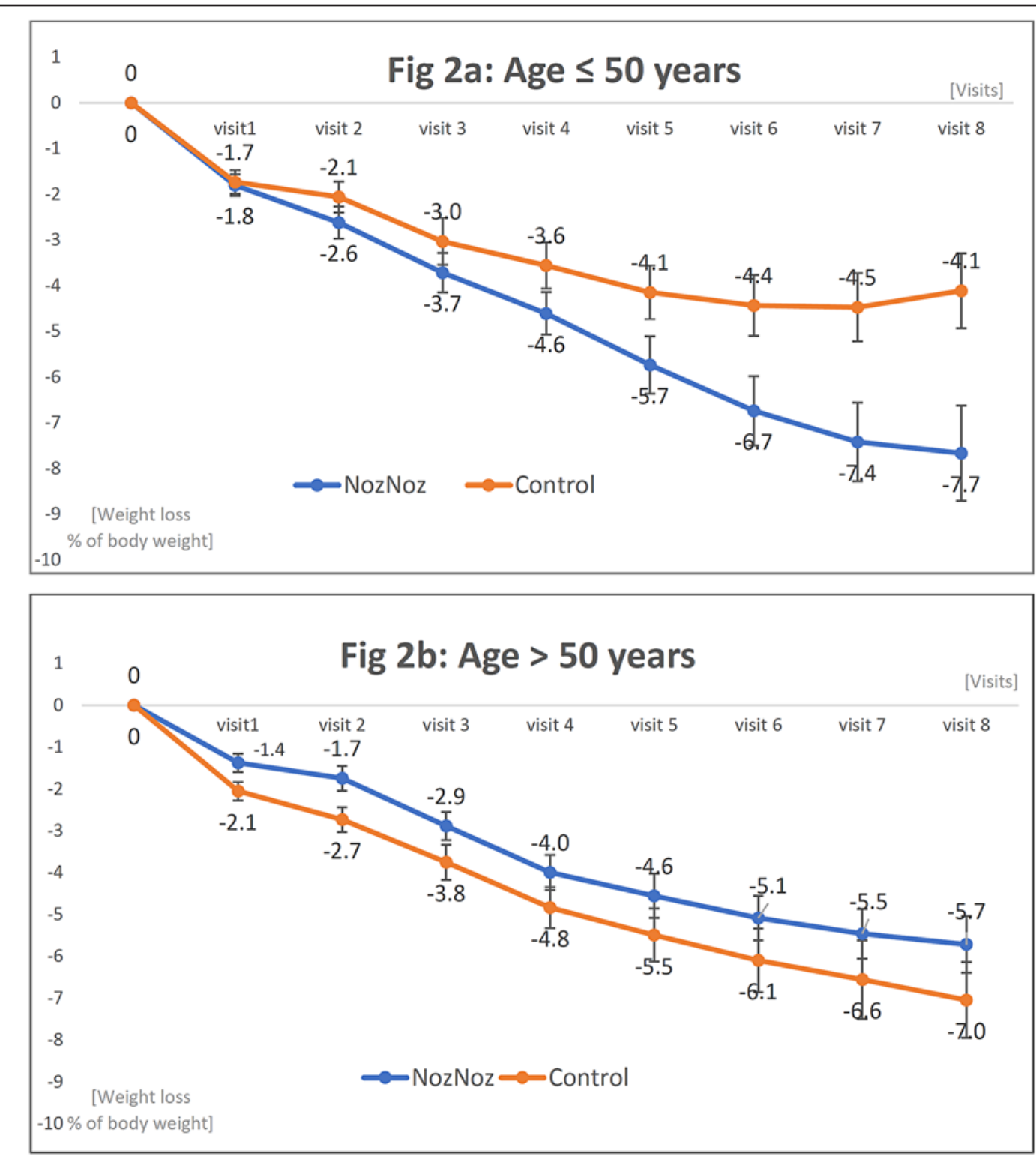

(Total number of observations at each visit: 65, young device:16, young control:13, old device:21, old control:15)

Fig. 2. Weight loss according to percentage of body weight, by age group. a Age $\leq 50$ years. $\mathbf{b}$ Age $>50$ years. This figure shows the weight loss in percentage of body weight in each of the visits at the clinic from baseline to the end of the study, for device and control groups. a The above is shown for participants aged $\leq 50$ years - where the difference is highly significant. $\mathbf{b}$ The above is shown for participants aged $>50$ years where there is no difference.

The analysis yielded a significant linear effect of treatment by group by age. This was evidenced by a linear and steady decrease in body weight among participants aged $\leq 50$ years in the device group. In contrast, the reduction in weight for the same-age participants in the control group was not linear. The linear effect of treatment remained significant for the interaction of intervention and age also when weight loss was assessed as the percentage of body weight and as change in BMI. A steady and linear reduction in both parameters was observed in participants aged $\leq 50$ years in the device, but not the control group ( $p=0.02$ for both 


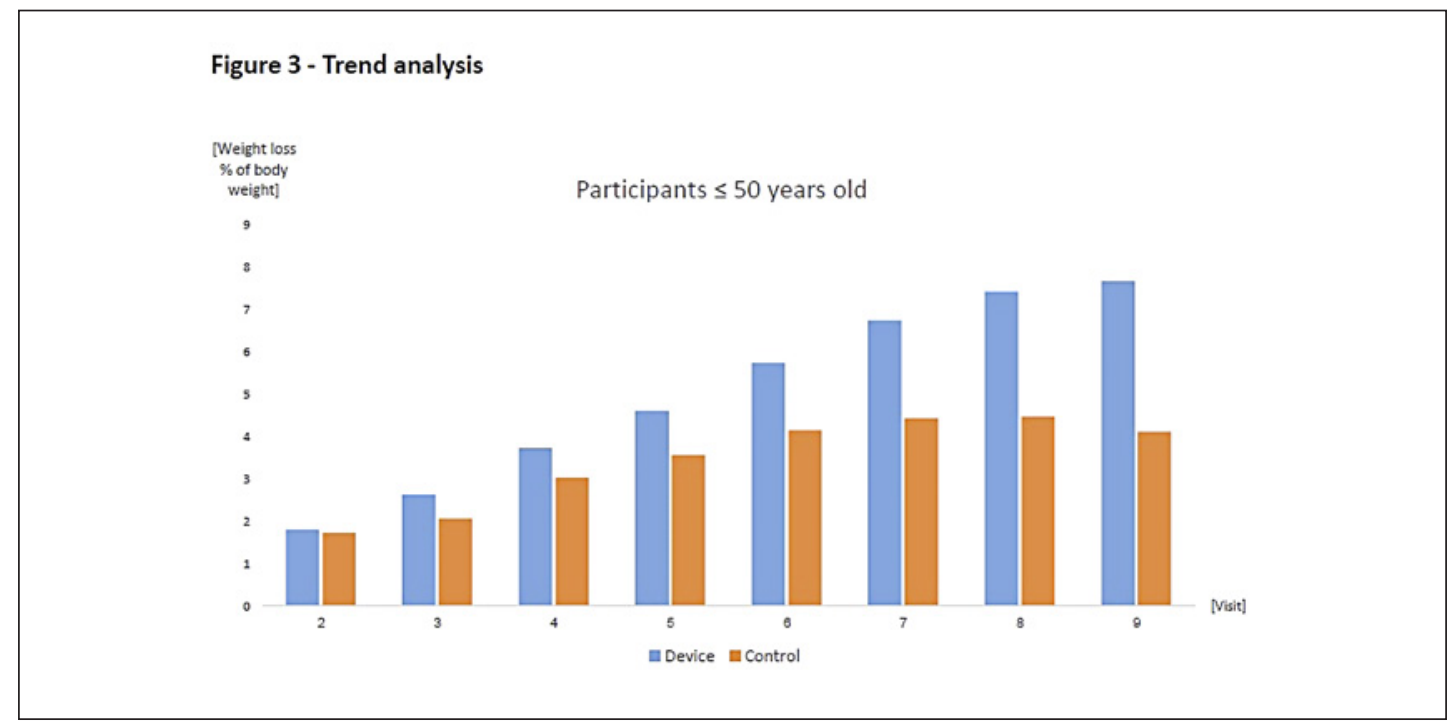

Fig. 3. Trend analysis. This figure shows the linear and steady decrease in percentage of body weight among participants aged $\leq 50$ years in the device group and in contrast, that the reduction for the same-age participants in the control group was not linear. In this figure it is demonstrated that the linear effect remained significant also when comparing 8 time points of measurements $(p=0.02$; when removing the baseline BMI before joining the program).

parameters). The linear effect remained significant also when comparing 8 time points of measurements ( $p=0.02$; when removing the baseline BMI before joining the program; Fig. 3 ).

\section{Dietary Intake}

At the end of the 12-week study period, a higher proportion of participants in the device than the control group reported reduced consumption of sugar $(p<0.02)$, sweetened beverages $(p<0.001)$, and artificial sweeteners $(p<0.02$; Fig. $4 \mathrm{a}-\mathrm{c})$. These significant differences between the intervention groups in dietary preferences were driven mainly by the younger age group (Fig. $4 a-c$ ). For age $\leq 50$ years, the statistical significance of the differences between the intervention groups was greater for sugar, sweetened beverages, and alcoholic beverages $(p<0.0001)$ than for artificial sweeteners $(p=0.03)$.

\section{Metabolic Values}

At the end of the 12-week study period, mean serum insulin $(-1.5 \pm 3.5$ units, $p=0.02)$ and HOMA-IR $(-0.51 \pm 0.95, p=0.01)$ were reduced significantly in the device group, but not in the control group $(+0.4 \pm 5.0$ units and $0.00 \pm 1.35$, respectively). For participants aged $\leq 50$ years, HOMA-IR decreased in the device group $(p<0.05)$ but not in the control group. No significant differences were observed between the intervention groups in serum glucose, cholesterol, triglycerides, and low-density lipoprotein, from baseline to the end of the 12 -week study period (Table 2).

\section{Discussion}

This study demonstrated efficacy and safety of a removable nasal device NozNoz ${ }^{\mathrm{TM}}$. Compared to a control group, food preferences were altered, and metabolic variables improved following 12 weeks of use of the device. In adults aged $\leq 50$ years, the mean weight

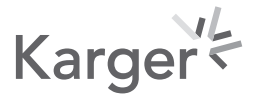




\begin{tabular}{|c|c|c|}
\hline & & \\
\hline & Obes Facts 2020;13:473-486 & \\
\hline Obesity Facts & DOI: $10.1159 / 000508976$ & $\begin{array}{l}\text { (c) } 2020 \text { The Author(s). Published by S. Karger AG, Basel } \\
\text { www.karger.com/ofa }\end{array}$ \\
\hline
\end{tabular}

Dicker et al.: Weight Loss following the Use of a Novel Smell-Reducing Device

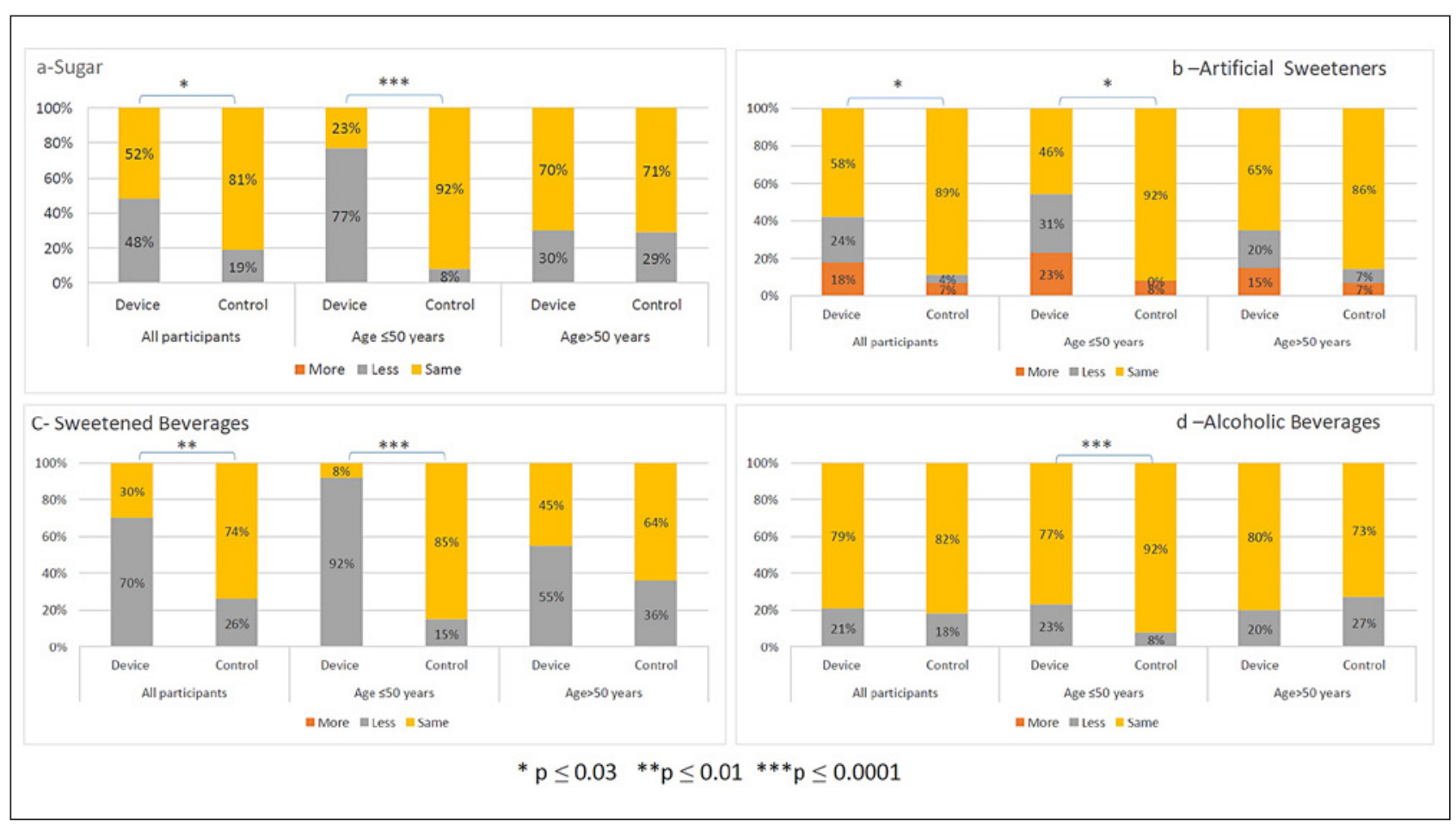

Fig. 4. Changes in dietary preferences during the 12-week study period, according to intervention and age group. a Sugar. b Artificial sweeteners. c Sweetened beverages. d Alcoholic beverages. These graphs show the percentage of participants in each intervention group, who reported reduction in consumption, increase of consumption and no change in consumption of food/drinks. a A significantly higher percentage of participants in the device group relatively to the control group reported reduction in the consumption of sugar: these data are significant for all ages $(p \leq 0.03)$ and separately for participants aged $\leq 50(p \leq 0.0001)$. b A significantly higher percentage of participants in the device group relatively to the control group reported reduction in the consumption of artificial beverages: these data are significant for all ages $(p \leq 0.03)$ and separately for participants aged $\leq 50(p \leq 0.03)$. c A significantly higher percentage of participants in the device group relatively to the control group reported reduction in the consumption of sweet beverages: these data are significant for all ages $(p \leq 0.001)$ and separately for participants aged $\leq 50(p \leq 0.0001)$. d A significantly higher percentage of participants in the device group relatively to the control group for participants aged $\leq 50$ reported reduction in the consumption of alcoholic beverages: these data are significant only for participants aged $\leq 50(p \leq 0.0001)$.

loss was almost double that of the control group. We assume that this difference between the age groups is related to a lesser sense of smell observed in older adults, as has been documented in the literature [7-12]. Alternatively, the lack of difference in weight loss between the intervention groups, among the older participants, could be related to the tendency of older persons to lose more weight with diet and exercise interventions than younger persons, possibly due to better compliance. However, persons on "active" treatments tend to rely on the treatment and this may diminish their adherence to a diet and exercise program. Accordingly, it is possible that the participants in the device group were less attentive to their diet plan than were those in the control group, consequent to their use of a more invasive treatment.

Nevertheless, an age-related difference was not observed in the current study, in which sense of smell was assessed using n-butanol. This discrepancy may be due to the complexity of the change in the sense of smell with age, which was not assessed in this study. Accordingly, several studies have shown a decrease in the ability to smell many food odors in elderly indi- 
Dicker et al.: Weight Loss following the Use of a Novel Smell-Reducing Device

viduals, while the ability to smell some types of chemical odors and fruits is better preserved $[7,10-12]$. Moreover, a number of studies showed differences in smell when food odors and non-food odors were tested [17-19]. In those studies, participants with overweight or obesity were more sensitive to food odors and reacted more strongly than did people with normal weight. In contrast, a recent meta-analysis concluded that people with obesity tend to have reduced smelling capacity [27]; however, that study did not analyze the data according to the particular sense of smell of food odors.

Considering the cohort as a whole, some improvement was observed in the device group, in both insulin and HOMA-IR levels, but not in the control group. This difference between the interventions in metabolic parameters was evident despite the lack of a significant difference in weight reduction. This suggests a possible metabolic effect of smell blunting, independent of weight loss. A larger cohort is needed to verify this point.

The possible mechanisms that may underly associations of sense of smell and changes in weight and metabolic variables are complex and apparently evolution-related. Olfactory neurons in the nasal cavity connect to the olfactory bulb, which is a direct extension of the brain. Several hormones and transcription factors are involved in smell, food intake, body weight, and energy expenditure, including leptin, insulin, ghrelin, glucagon-like peptide-1 (GLP-1), insulin-like growth factor-1 (IGF1), orexin, neuropeptide Y, endocannabinoids, and cholecystokinin [5, 6, 14, 27-30]. Of particular interest are receptors for several gut hormones in the nasal olfactory epithelium and the olfactory bulb, and in other brain areas that connect to the olfactory system [5].

Ghrelin hormone, which is known to increase food intake, also increases sniffing behavior in both rats and humans [31]. Sniffing increases the amount of odor molecules that reach the olfactory epithelium, and increases the ability to smell odors [31,32]. Fernández-Aranda and colleagues [13, 14] and Sun et al. [33] demonstrated that compromised phasic ghrelin suppression is associated with increased olfactory perception and decreased satiety response to odors. Leptin, a hormone increased in obesity, is intimately tied with olfaction. Baly et al. [34] demonstrated the presence of several isoforms of leptin receptors in the nasal epithelium of rodents and showed that leptin is actually synthesized locally in the olfactory mucosa. Obese rats were shown to have greater food-seeking behavior when exposed to both novel and familiar food olfactory cues [35], but this behavior in rodents returned to normal with leptin injections [36]. After infusion of leptin and orexin into the cerebral spinal space, orexin increased olfactory sensitivity, and leptin decreased sensitivity [37]. The investigators concluded that the modulation by orexin and leptin of olfactory performance is similar to the physiological induction of fasting and satiation. Further, these appear to be important factors in the interdependency of olfaction and food intake. Numerous insulin receptors are present in the olfactory bulb, and both intravenous and intranasal insulin administration were shown to reduce olfaction in healthy humans $[15,38]$. Paradoxically, in individuals with an impaired sense of smell, intranasal insulin enhances sensitivity, intensity, and discrimination [16]. IGF1 receptors in olfactory sensory neurons were found to be critical in olfaction [6]. Following loss of IGF1 receptors in olfactory sensory neurons, olfaction improved, and adiposity and insulin resistance increased [6]. GLP-1 appears critical for smell and taste, and GLP-1 receptors were detected in the olfactory bulb and olfactory cortex of rats $[39,40]$. GLP-1 was shown to be associated with weight loss, decreased food intake, altered dietary preferences, and improvements in insulin resistance and glucose tolerance, and is greatly increased after gastric bypass surgery for obesity [21, 22]. Diacetyl, a volatile compound used to enhance flavor and palatability in food, suppresses GLP-1 in enteroendocrine cells [41] and may be associated with increased food intake. Finally, studies in mice show that knocking out the smelling sensors in the olfactory apparatus leads to weight loss, increased thermogenesis and fat burn, and increased insulin sensitivity [6]. 
Dicker et al.: Weight Loss following the Use of a Novel Smell-Reducing Device

Considering the entire cohort, a higher proportion of persons in the device than the control group reported reduced intake of sugar, artificial sweeteners, and sweetened beverages, and reported paying more attention to healthy eating habits. The reduced consumption of both sugar and artificial sweeteners suggests that the decreased intake of sugar was likely due to a reduced craving for sweets, rather than a desire to reduce caloric intake. This concurs with the finding of a $48 \%$ reduction in consumption of sweet beverages, and a $37 \%$ reduction in consumption of sweets in individuals who had disordered or completed loss of smell [24]. In addition, alcohol consumption reportedly decreased in the device but not the control group. This result is consistent with a study in humans that showed that brain areas activated by food odors are similar to those elicited by cues of addictive substances, such as alcohol [28]. In the device group of the current cohort, improvements in dietary habits were only observed for the younger group, as shown in Figure 4c.

The better outcomes in the device versus the control group for persons aged $\leq 50$ years compared to $>50$ years has clinical and research implications. First, the findings suggest that interventions aimed to increase weight loss by means of reducing smell sense should be targeted to younger populations. Second, directing future studies to younger individuals may help to elucidate mechanisms by which the novel nasal device contributes to weight loss and metabolic improvements.

This study had a number of limitations. These include the use of n-butanol rather than food odors to assess olfaction, the relatively small number of participants who completed the study, and the availability of only 2 nasal device sizes, which may have limited the smell blunting in some persons.

In conclusion, a novel drug-free nasal device that causes sense of smell reduction, while inserted in the nose, holds promise to promote weight loss, at least in persons up to age 50 years, to help promote healthy food preferences including lower sweet intake, and to improve metabolic parameters. Further studies are needed to determine the role of this device in the treatment of obesity and diabetes.

\section{Acknowledgments}

We thank the staffs of Hasharon Hospital, Rabin Medical Center, Petach Tikva, Israel and Haemek Medical Center, Afula, Israel for their assistance in caring for the study participants and collecting data, and Beck Medical for supporting the research.

\section{Statement of Ethics}

The study complied with the guidelines for human studies and was conducted in accordance with the World Medical Association Declaration of Helsinki. The study protocol was approved by the Institutional Review Boards of Rabin Medical Center and Haemek Medical Center and by the Israeli Ministry of Health. All study participants provided their written informed consent to participate in the study.

\section{Conflict of Interest Statement and Funding Sources}

This study was sponsored by Beck Medical, Givat-Ada, Israel. D.D. received a consultant fee from Beck Medical. A.B. is the majority owner of Beck Medical. E.G. is a consultant to Beck Medical and owns shares of the company. R.L.A. is an unpaid consultant to Beck Medical and 
Dicker et al.: Weight Loss following the Use of a Novel Smell-Reducing Device

owns options to buy shares in the future. A.M., D.M., S.M., and M.S. declare no conflicts of interest. Beck Medical Ltd. Is the owner of all patents related to this paper.

\section{Author Contributions}

D.D. contributed to the design, interpretation of the data, drafting, and revision of the manuscript of the study. All authors reviewed and approved the final, submitted version.

\section{References}

1 WHO. Double-duty actions for nutrition. Policy Brief. Geneva, 2017. Available from: http://apps.who.int/iris/ bitstream/handle/10665/255414/WHO-NMH-NHD-17.2-eng.pdf?ua=1.

2 NCD Risk Factor Collaboration (NCD-RisC). Trends in adult body-mass index in 200 countries from 1975 to 2014: a pooled analysis of 1698 population-based measurement studies with $19 \cdot 2$ million participants. Lancet. 2016 Apr;387(10026):1377-96.

3 UNICEF. WHO WBG: Levels and trends in child malnutrition: key findings of the 2018 edition of the Joint Child Malnutrition Estimates. Geneva, 2018 [cited Julz 10, 2018]. Available from: http://www.who.int/ nutgrowthdb/2018-jme-brochure.pdf?ua=1.

4 Haslam DW, James WP. Obesity. Lancet. 2005 Oct;366(9492):1197-209.

5 Palouzier-Paulignan B, Lacroix MC, Aimé P, Baly C, Caillol M, Congar P, et al. Olfaction under metabolic influences. Chem Senses. 2012 Nov;37(9):769-97.

6 Riera CE, Tsaousidou E, Halloran J, Follett P, Hahn O, Pereira MM, et al. The Sense of Smell Impacts Metabolic Health and Obesity. Cell Metab. 2017 Jul;26(1):198-211.e5.

7 Doty RL, Kamath V. The influences of age on olfaction: a review. Front Psychol. 2014 Feb;5:20.

8 Murphy C, Nordin S, de Wijk RA, Cain WS, Polich J. Olfactory-evoked potentials: assessment of young and elderly, and comparison to psychophysical threshold. Chem Senses. 1994 Feb;19(1):47-56.

9 Buschhüter D, Smitka M, Puschmann S, Gerber JC, Witt M, Abolmaali ND, et al. Correlation between olfactory bulb volume and olfactory function. Neuroimage. 2008 Aug;42(2):498-502.

10 Duffy VB, Backstrand JR, Ferris AM. Olfactory dysfunction and related nutritional risk in free-living, elderly women. J Am Diet Assoc. 1995 Aug; 95(8):879-84.

11 Schiffman S, Pasternak M. Decreased discrimination of food odors in the elderly. J Gerontol. 1979 Jan;34(1): 73-9.

12 Sinding C, Puschmann L, Hummel T. Is the age-related loss in olfactory sensitivity similar for light and heavy molecules? Chem Senses. 2014 Jun;39(5):383-90.

13 Fernández-Aranda F, Agüera Z, Fernández-García JC, Garrido-Sanchez L, Alcaide-Torres J, Tinahones FJ, et al. Smell-taste dysfunctions in extreme weight/eating conditions: analysis of hormonal and psychological interactions. Endocrine. 2016 Feb;51(2):256-67.

14 Pastor A, Fernández-Aranda F, Fitó M, Jiménez-Murcia S, Botella C, Fernández-Real JM, et al. A Lower Olfactory Capacity Is Related to Higher Circulating Concentrations of Endocannabinoid 2-Arachidonoylglycerol and Higher Body Mass Index in Women. PLoS One. 2016 Feb;11(2):e0148734.

15 Brünner YF, Benedict C, Freiherr J. Intranasal insulin reduces olfactory sensitivity in normosmic humans. J Clin Endocrinol Metab. 2013 Oct; 98(10):E1626-30.

16 Schöpf V, Kollndorfer K, Pollak M, Mueller CA, Freiherr J. Intranasal insulin influences the olfactory performance of patients with smell loss, dependent on the body mass index: A pilot study. Rhinology. 2015 Dec; 53(4):371-8.

17 Ferriday D, Brunstrom JM. 'I just can't help myself': effects of food-cue exposure in overweight and lean individuals. Int J Obes. 2011 Jan;35(1):142-9.

18 Stafford LD, Whittle A. Obese individuals have higher preference and sensitivity to odor of chocolate. Chem Senses. 2015 May;40(4):279-84.

19 Jansen A, Theunissen N, Slechten K, Nederkoorn C, Boon B, Mulkens S, et al. Overweight children overeat after exposure to food cues. Eat Behav. 2003 Aug;4(2):197-209.

20 Fedoroff I, Polivy J, Herman CP. The specificity of restrained versus unrestrained eaters' responses to food cues: general desire to eat, or craving for the cued food? Appetite. 2003 Aug;41(1):7-13.

21 Holinski F, Menenakos C, Haber G, Olze H, Ordemann J. Olfactory and Gustatory Function After Bariatric Surgery. Obes Surg. 2015 Dec;25(12):2314-20.

22 Makaronidis JM, Neilson S, Cheung WH, Tymoszuk U, Pucci A, Finer N, et al. Reported appetite, taste and smell changes following Roux-en-Y gastric bypass and sleeve gastrectomy: effect of gender, type 2 diabetes and relationship to post-operative weight loss. Appetite. 2016 Dec;107:93-105.

23 Mattes RD, Cowart BJ, Schiavo MA, Arnold C, Garrison B, Kare MR, et al. Dietary evaluation of patients with smell and/or taste disorders. Am J Clin Nutr. 1990 Feb;51(2):233-40. 
24 Aschenbrenner K, Hummel C, Teszmer K, Krone F, Ishimaru T, Seo HS, et al. The influence of olfactory loss on dietary behaviors. Laryngoscope. 2008 Jan;118(1):135-44.

25 Lushchak OV, Carlsson MA, Nässel DR. Food odors trigger an endocrine response that affects food ingestion and metabolism. Cell Mol Life Sci. 2015 Aug;72(16):3143-55.

26 Cain WS, Rabin MD. Comparability of two tests of olfactory functioning. Chem Senses. 1989;14(4):479-85.

27 Martin B, Dotson CD, Shin YK, Ji S, Drucker DJ, Maudsley S, et al. Modulation of taste sensitivity by GLP-1 signaling in taste buds. Ann N Y Acad Sci. 2009 Jul;1170(1):98-101.

28 Bragulat V, Dzemidzic M, Bruno C, Cox CA, Talavage T, Considine RV, et al. Food-related odor probes of brain reward circuits during hunger: a pilot FMRI study. Obesity (Silver Spring). 2010 Aug;18(8):1566-71.

29 Peng M, Coutts D, Wang T, Cakmak YO. Systematic review of olfactory shifts related to obesity. Obes Rev. 2019 Feb;20(2):325-38.

30 Belgardt BF, Brüning JC. CNS leptin and insulin action in the control of energy homeostasis. Ann N Y Acad Sci. 2010 Nov;1212(1):97-113.

31 Tong J, Mannea E, Aimé P, Pfluger PT, Yi CX, Castaneda TR, et al. Ghrelin enhances olfactory sensitivity and exploratory sniffing in rodents and humans. J Neurosci. 2011 Apr;31(15):5841-6.

32 Verhagen JV, Wesson DW, Netoff TI, White JA, Wachowiak M. Sniffing controls an adaptive filter of sensory input to the olfactory bulb. Nat Neurosci. 2007 May;10(5):631-9.

33 Sun X, Veldhuizen MG, Babbs AE, Sinha R, Small DM. Perceptual and Brain Response to Odors Is Associated with Body Mass Index and Postprandial Total Ghrelin Reactivity to a Meal. Chem Senses. 2016 Mar; 41(3): 233-48.

34 Baly C, Aioun J, Badonnel K, Lacroix MC, Durieux D, Schlegel C, et al. Leptin and its receptors are present in the rat olfactory mucosa and modulated by the nutritional status. Brain Res. 2007 Jan;1129(1):130-41.

35 Thanos PK, Robison LS, Robinson JK, Michaelides M, Wang GJ, Volkow ND. Obese rats with deficient leptin signaling exhibit heightened sensitivity to olfactory food cues. Synapse. 2013 Apr;67(4):171-8.

36 Getchell TV, Kwong K, Saunders CP, Stromberg AJ, Getchell ML. Leptin regulates olfactory-mediated behavior in ob/ob mice. Physiol Behav. 2006 May;87(5):848-56.

37 Julliard AK, Chaput MA, Apelbaum A, Aimé P, Mahfouz M, Duchamp-Viret P. Changes in rat olfactory detection performance induced by orexin and leptin mimicking fasting and satiation. Behav Brain Res. 2007 Nov; 183(2): 123-9.

38 Ketterer C, Heni M, Thamer C, Herzberg-Schäfer SA, Häring HU, Fritsche A. Acute, short-term hyperinsulinemia increases olfactory threshold in healthy subjects. Int J Obes. 2011 Aug;35(8):1135-8.

39 Merchenthaler I, Lane M, Shughrue P. Distribution of pre-pro-glucagon and glucagon-like peptide-1 receptor messenger RNAs in the rat central nervous system. J Comp Neurol. 1999 Jan;403(2):261-80.

40 Alvarez E, Roncero I, Chowen JA, Thorens B, Blázquez E. Expression of the glucagon-like peptide-1 receptor gene in rat brain. J Neurochem. 1996 Mar;66(3):920-7.

41 McCarthy T, Bruen C, O'Halloran F, Schellekens H, Kilcawley K, Cryan JF, et al. Aroma compound diacetyl suppresses glucagon-like peptide-1 production and secretion in STC-1 cells. Food Chem. 2017 Aug;228: $35-42$. 